\title{
Tart cherry juice consumed daily for 4 weeks does not impair or exacerbate biomarkers of metabolic function in at-risk overweight and obese subjects: A randomized, crossover pilot study
}

\author{
KEITH R. MARTIN ${ }^{1}$, LACEY BURRELL ${ }^{2}$ and JENNIFER BOPP ${ }^{2}$ \\ ${ }^{1}$ Center for Nutraceutical and Dietary Supplement Research, College of Health Sciences, University of Memphis, \\ Memphis, TN 38152; ${ }^{2}$ Healthy Lifestyles Research Center, Arizona State University, Phoenix, AZ 85004, USA
}

Received May 30, 2020; Accepted November 10, 2020

DOI: $10.3892 /$ ijfn.2020.12

\begin{abstract}
Currently, there is a worldwide epidemic of obesity, diabetes and cardiovascular disease (CVD), largely due to increased dietary caloric intake. A number of scientists and experts assert that the increased consumption of caloric sugar-sweetened beverages (SSBs) has significantly contributed to the risk of developing chronic disease, particularly obesity, since the worldwide consumption of sucrose has tripled over the past 50 years. With these trends, perturbations in metabolic biomarkers have often been noted. Thus, the present study examined whether the consumption of $8 \mathrm{oz} /$ day $(240 \mathrm{ml} /$ day) of $100 \%$ tart cherry juice (TCJ) would adversely affect metabolic parameters in at-risk individuals. The present study was a 10 -week $2 \times 2$ crossover, randomized, placebo-controlled dietary intervention in overweight and obese participants (BMI $\geq 25.0 \mathrm{~kg} / \mathrm{m}^{2}$ ). Participants were randomly assigned to consume for 4 weeks either $100 \%$ TCJ ( $240 \mathrm{ml} /$ day) or a generic fruit punch followed by a 2 -week washout and subsequent consumption of the alternate beverage for an additional 4 weeks. Comprehensive metabolic panels (hepatic and renal function), anthropometric measures, and food intake and physical activity questionnaires were collected and analyzed at 0, 4, 6 and 10 weeks. No significant alterations
\end{abstract}

Correspondence to: Dr Keith R. Martin, Center for Nutraceutical and Dietary Supplement Research, College of Health Sciences, University of Memphis, 495 Zach H. Curlin Street, Memphis, TN 38152, USA

E-mail: krmrtin4@memphis.edu

Abbreviations: ALP, alkaline phosphatase; ALT, alanine aminotransferase; AST, aspartate aminotransferase; BMI, body mass index; CKD, chronic kidney disease; CVD, cardiovascular disease; ESR, erythrocyte sedimentation rate; HFCS, high-fructose corn syrup; NAFLD, non-alcoholic fatty liver disease; SSBs, sugar-sweetened beverages; TC, total cholesterol; TCJ, tart cherry juice; T2DM, type 2 diabetes mellitus; TG, triglycerides

Key words: tart cherry juice, overweight/obese, metabolic syndrome, liver/kidney function
$(\mathrm{P}>0.05)$ in hepatic or renal function were noted from the start to the end of the study when comparing the TCJ to the placebo group. Moreover, there were no significant changes $(\mathrm{P}>0.05)$ in fasting blood glucose concentrations between pre- and post-consumption time points for either the placebo or TCJ groups. Dietary intake and physical activity levels were similar among all groups. In addition, no changes in body composition (percent body fat, lean body mass, etc.) or BMI were noted after 4 weeks of beverage consumption. It was thus concluded that $100 \%$ TCJ does not exacerbate already existing risk factors in an at-risk population and does not adversely affect hepatic or renal function.

\section{Introduction}

Currently, there is a worldwide epidemic of obesity, type 2 diabetes mellitus (T2DM) and cardiovascular disease (CVD) largely thought to be due to increased dietary caloric intake (1-3). A number of scientists and experts assert that the increased consumption of sugar-sweetened beverages (SSBs) has significantly contributed to these trends, particularly obesity, since the worldwide consumption of sucrose has tripled over the past 50 years (4-6). In the USA, $77 \%$ of all calories purchased from 2005-2009 contained sweeteners of which corn syrup, cane sugar, high-fructose corn syrup (HCFS) and fruit juice concentrate were listed as the most commonly used (7). A high SSB consumption reportedly contributes to a $12 \%$ increased risk of hypertension, $26 \%$ increased risk for T2DM and a 19\% increased risk of CVD, suggesting that further research is required regarding dietary sources of simple sugars [mono-(glucose and fructose) and disaccharide (sucrose)] contained in beverages, such as fruit juice (8-10).

A conundrum exists regarding the consumption of fruit juice. The argument in favor of $100 \%$ fruit juice as a healthy beverage derives from the fact that Americans of all ages do not meet their daily fruit requirement and $100 \%$ fruit juice offers most of the nutrients of whole fruit in a less expensive, more user-friendly form $(8,11)$. In fact, reducing or eliminating $100 \%$ fruit juice, and consequently nutrients and fiber contained within, could lead to unintended consequences, such as a reduced daily fruit intake and an increased consumption 
of less nutritious, calorie-dense beverages, such as soft drinks $(12,13)$. Moreover, numerous fruit juices are produced from exotic 'superfruits', such as noni, maqui, acai, goji, pomegranate, etc., due to their complement of beneficial bioactive, e.g., antioxidant, compounds, which can lead to robust health benefits $(14,15)$. However, there is limited published information available on the toxicity profiles of some dietary fruit juices due to their prevalence in the food supply, common use and the general lack of evidence that would support safety concerns. As a result, there seems to be a misconception that fruit juices and smoothies are also low-sugar alternatives to SSBs (4). Although fruit juices may generally be considered safe, chronic consumption, similar to dietary triglycerides (TG), could cause metabolic perturbations, contributing to the risk of developing chronic diseases, such as non-alcoholic fatty liver disease (NAFLD), e.g., liver toxicity and renal dysfunction (16-18).

Fruit juices have been shown to induce mild to moderate adverse effects on typical metabolic biomarkers in different experimental models. For example, in rodent studies, the provision of fruit juice for $48 \mathrm{~h}$ significantly and dose-dependently increased liver enzyme, urea and creatinine levels, suggesting both nephrotoxicity and hepatotoxicity $(19,20)$. In another study, the ingestion of pomegranate was associated with the deaths of young cattle without prior clinical signs, although gross subclinical pathological changes indicated hepatotoxicity (21). In a study on noni fruit (Morinda citrifolia), female mice fed fruit extracts for 6 months displayed chronic toxicity with clear hepatocellular necrosis, morphological changes in liver, and death after 3 months (22). In humans, cases of hepatotoxicity have also been reported following the consumption of noni juice. In two human case studies reported by Stadlbauer et al in a single report, individuals developed sub-acute hepatic failure and acute hepatitis following the consumption of 1.51 juice for 3 weeks and 21 juice for 3 months, respectively (23). The bottle gourd (Lagenaria siceraria), also known as lauki, ghia or dudhi, prescribed as part of traditional medicine, has been shown to cause numerous signs and symptoms of gastrointestinal and hepatic injury (24). Collectively, there are instances where dietary and/or medicinal fruit juices have increased the risk of hepatotoxicity.

Beverages, such as SSBs may also influence the risk of developing kidney disease (18). In the Jackson Heart Study $(n=3,003)$ a higher consumption of SSBs was shown to elevate the risk of chronic kidney disease (CKD) in a community-based cohort of African-Americans (25). In the Tehran Lipid and Glucose Study $(n=1,690)$, the consumption of $>4$ servings of SSBs was associated with a higher prevalence and incidence of CKD (26). In the Atherosclerosis Risk in Communities Study $(\mathrm{n}=15,745)$ the consumption of $1 \mathrm{SSB} /$ day increased the prevalence of hyperuricemia and CKD with an odds ratio of 2.59 for those consuming $>1 \mathrm{SSB} /$ day (17). As mentioned previously, the consumption of star fruit juice also induces kidney degeneration and necrosis compared to the controls, indicating nephrotoxicity (19). In at least one case report, an individual who consumed star fruit developed acute kidney failure requiring dialysis (27). Thus, there are data suggesting the potential for some dietary and/or medicinal fruit juices to cause nephrotoxicity.
Emerging evidence supports the robust complement and activities of bioactive molecules in functional foods, e.g., tart cherries and beverages, such as tart cherry juice (TCJ). The authors have conducted studies previously with TCJ investigating the effects of consumption on inflammatory markers and uric acid in humans, and currently report on the effects of TCJ on body composition or metabolic parameters in at-risk individuals. The present study enlisted overweight and obese individuals at a higher risk for cardiometabolic abnormalities (due to increased adiposity) compared to those with normal body weights (BMI $<25.0 \mathrm{~kg} / \mathrm{m}^{2}$ ) to consume $100 \%$ TCJ or the placebo beverage for 4 weeks ( $8 \mathrm{oz} / \mathrm{day} ; 240 \mathrm{ml} / \mathrm{day}$ ) to determine whether there were any changes in the levels of biomarkers of renal and/or hepatic function.

\section{Materials and methods}

Study subjects. The present study was a 10 -week $2 \times 2$ crossover, randomized, placebo-controlled dietary intervention in overweight and obese participants $\left(B M I \geq 25.0 \mathrm{~kg} / \mathrm{m}^{2}\right.$ ) who were $\geq 18$ years old. Respondents were excluded if they were pregnant, diabetic, displaying unresolved infections or diseases (inflammation, CVD, cancer, inflammatory bowel disease and liver disease), and were current smokers (including e-cigarettes). Histories of medication and dietary supplement use were collected, and participants taking anti-inflammatory or lipid-lowering medications were excluded. The respondents were screened initially by telephone using a preliminary medical questionnaire to rule out underlying medical conditions. All subjects provided written informed consent. The protocols in the present study were approved by the Institutional Review Board at Arizona State University. This trial is registered with ClinicalTrials.gov with identifier, NCT03638362.

Following enrollment, the subjects were randomly assigned to consume either 8 ounces of $100 \%$ TCJ (R.W. Knudsen) or a generic, artificially flavored red fruit punch for 4 weeks with 5 patients per group. Following a 2 -week washout period, the subjects were switched to the alternate beverage for an additional 4 weeks (Fig. 1). Participants were instructed to refrain from consuming other darkly pigmented fruits and juices during the study period, and were provided a detailed list with specific items, i.e., cherries, to avoid. Compliance was monitored by the review of diet records, a verbal interview and the return of empty beverage containers.

Dietary, medical and physical activity questionnaires and records were maintained by subjects and collected and reviewed by study personnel. The diet record listed all foods and beverages consumed (including placebo and tart cherry beverages), means of preparation, time of consumption, and amount/portion size and was analyzed using Food Processor Nutrition and Fitness Software (ESHA, version 8.5). The medical questionnaire included information on the use, dosage and frequency for medication and the use of dietary supplements. Physical activity was assessed by self-reporting using a standardized questionnaire and overall physical activity and/or exercise determined using a standardized scoring rubric.

Anthropometry. Following a $\geq 12$-h fast, participants reported to the laboratory for the measurement of body weight (via calibrated scale), height (via calibrated stadiometer) and body 
Table I. Macronutrient and energy intake by the study participants.

\begin{tabular}{lccr}
\hline Nutrient & Placebo & Treatment & P-value \\
\hline Energy, kcal/day & $1,816 \pm 417$ & $1,782 \pm 452$ & 0.685 \\
Protein $^{\mathrm{a}}$, g/day & $66 \pm 15$ & $61 \pm 0.6$ & 0.228 \\
Carbohydrate, g/day & $257 \pm 70$ & $255 \pm 69$ & 0.382 \\
Total fat $^{\mathrm{b}}, \mathrm{g} /$ day & $57 \pm 70$ & $56 \pm 16$ & 0.377 \\
\hline
\end{tabular}

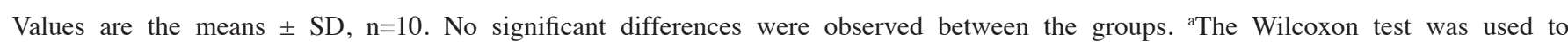

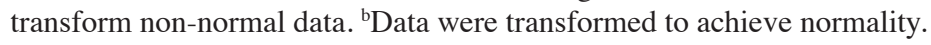

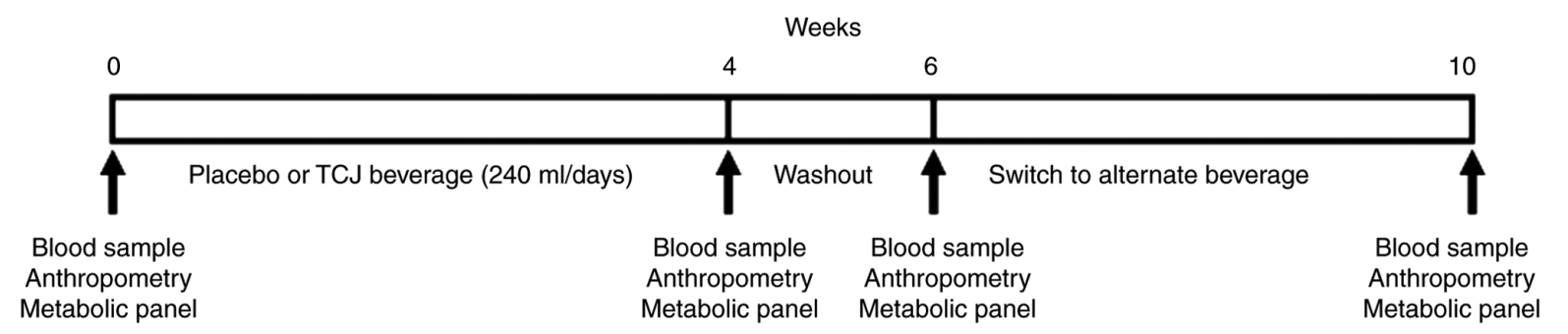

Figure 1. Experimental design of the present study. Following enrollment, the subjects were randomly assigned to consume either 8 ounces of $100 \%$ TCJ (R.W. Knudsen) or a generic, artificially flavored red fruit punch for 4 weeks. Following a 2-week washout period, the subjects were switched to the alternate beverage for an additional 4 weeks. TCJ, tart cherry juice.

composition [body fat percentage, fat mass, fat-free mass, total body water, basal metabolic rate (BMR)], as measured by bioelectrical impedance (TBF 300A Tanita Body Composition Analyzer). BMI and BMR were recalculated at each visit.

Biomedical analysis. Fasting blood samples were drawn by standard venipuncture protocols into lithium heparin vacutainer tubes (Thermo Fisher Scientific, Inc.). A comprehensive metabolic panel reagent disc, which included an assay for glucose, was used to concurrently measure biomarkers of liver function [alanine aminotransferase (ALT), aspartate aminotransferase (AST), albumin, total protein, total bilirubin and alkaline phosphatase (ALP)] and nitrogen balance/kidney function [blood urea nitrogen (BUN), creatinine and albumin], using a Piccolo Blood Chemistry Analyzer (Abaxis Inc.). Briefly, $100 \mu \mathrm{l}$ of whole blood was transferred from each vacutainer (prior to centrifugation) to a reaction disc (Piccolo Comprehensive Metabolic Panel, Abaxis, CA) with preloaded, partitioned, test-specific reagents including diluents, surfactants, and preservatives for each tested analyte (sodium, potassium, total protein, total carbon dioxide, total bilirubin, blood urea nitrogen, calcium, AST, ALP, albumin, ALT and glucose). For a description of the specific reactions for analytes, please refer to www.abaxis.com. Remaining blood was centrifuged at $1,100 \mathrm{x}$ g at $4^{\circ} \mathrm{C}$ for $20 \mathrm{~min}$ and plasma was archived in $0.5 \mathrm{ml}$ aliquots at $-80^{\circ} \mathrm{C}$.

Statistical analysis. All data obtained during the present study were analyzed using the Statistical Package for the Social Sciences (SPSS) version 17.0.2, 2009. Values are expressed as the means \pm standard deviation (SD). The sample size for the present study was 10 (5 participants began with the placebo intervention and 5 participants began with the treatment intervention). Differences in participant electrolyte and metabolite concentrations were considered significant at $\mathrm{P}<0.05$ and considered a trend at $\mathrm{P} \geq 0.1$ and $\mathrm{P}>0.05$. All data were tested for normality and transformed when necessary using the Friedman Test or Wilcoxon Signed Ranked Test. The means of each paired group were analyzed using the Student's t-test.

\section{Results}

Dietary intake and physical activity. Dietary records were collected and analyzed at each visit and, upon analysis; no significant differences in the dietary intake patterns of macronutrients or total energy were observed between the groups (Table I). The data presented in Table I, when expressed as the percentage of total caloric intake, e.g., kcal from fat/total daily kcals (from carbohydrates, proteins and fats), further indicated that the participants were consuming an average of $68.0 \pm 1.1,16.7 \pm 1.7$ and $15.3 \pm 2.0 \%$ of kcal from carbohydrates, proteins and fats, respectively. The Food and Nutrition Board of the Institutes of Medicine (IOM) recommends consumption levels for carbohydrates (45-65\% of energy), proteins (10-35\% of energy) and fat (20-35\% of energy), as indicated. The participants in the present study averaged marginally above the recommended range for carbohydrates and below the recommended levels for fat. No significant differences were noted in either physical activity or exercise levels and the participants as a group exhibited light to moderate overall activity.

Anthropometric measurements. Data for anthropometric indices for the participants were collected and analyzed; no significant differences were noted between any of the parameters between the groups (data not shown) The average body 
Table II. Physical characteristics and fasting glucose levels of the study participants.

\begin{tabular}{|c|c|c|c|c|c|c|c|c|c|c|}
\hline \multirow[b]{3}{*}{ Participant no. } & \multirow[b]{3}{*}{ Weight (kg) } & \multirow[b]{3}{*}{ Height (m) } & \multirow[b]{3}{*}{$\operatorname{BMI}\left(\mathrm{kg} / \mathrm{m}^{2}\right)$} & \multirow[b]{3}{*}{ Age (years) } & \multirow[b]{3}{*}{ Sex } & \multirow[b]{3}{*}{ Category } & \multicolumn{4}{|c|}{ Fasting glucose (mg/dl) } \\
\hline & & & & & & & \multicolumn{2}{|c|}{ Placebo } & \multicolumn{2}{|c|}{ TCJ } \\
\hline & & & & & & & Pre & Post & Pre & Post \\
\hline 1 & 96.16 & 1.82 & 27.3 & 40 & $\mathrm{~F}$ & Overweight & 92 & 94 & 97 & 100 \\
\hline 2 & 83.55 & 1.69 & 28.3 & 33 & M & Overweight & 94 & 91 & 100 & 97 \\
\hline 3 & 85.82 & 1.74 & 28.6 & 25 & $\mathrm{~F}$ & Overweight & 103 & 102 & 98 & 98 \\
\hline 4 & 106.51 & 1.60 & 29.2 & 61 & M & Overweight & 116 & 116 & 108 & 107 \\
\hline 5 & 94.08 & 1.64 & 29.3 & 54 & $\mathrm{~F}$ & Overweight & 89 & 94 & 93 & 94 \\
\hline 6 & 80.38 & 1.68 & 32 & 38 & $\mathrm{~F}$ & Obese & 97 & 99 & 98 & 96 \\
\hline 7 & 79.29 & 1.55 & 33 & 31 & $\mathrm{~F}$ & Obese & 99 & 103 & 106 & 113 \\
\hline 8 & 110.86 & 1.73 & 35.1 & 47 & $\mathrm{~F}$ & Obese & 117 & 114 & 110 & 107 \\
\hline 9 & 75.48 & 1.54 & 37.2 & 24 & $\mathrm{~F}$ & Obese & 105 & 109 & 103 & 108 \\
\hline 10 & 75.57 & 1.66 & 41.6 & 28 & $\mathrm{~F}$ & Obese & 88 & 88 & 93 & 92 \\
\hline Mean & 88.77 & 1.66 & 32.2 & 38.1 & $8: 2$ & $5: 5$ & 100 & 101 & 100.6 & 101.2 \\
\hline STD & 12.62 & 0.09 & 4.6 & 12.5 & $\mathrm{~F}: \mathrm{M}$ & ov/ob & 10.3 & 9.6 & 6 & 7 \\
\hline
\end{tabular}

TCJ, tart cherry juice.

Table III. Effects of beverage consumption on biochemical profile.

\begin{tabular}{|c|c|c|c|c|c|c|}
\hline \multirow[b]{2}{*}{ Biochemical parameter } & \multicolumn{2}{|c|}{ Placebo } & \multicolumn{2}{|c|}{ TCJ } & \multirow[b]{2}{*}{ Reference range } & \multirow{2}{*}{$\begin{array}{c}\text { P-value } \\
\text { placebo vs. TCJ }\end{array}$} \\
\hline & Pre & Post & Pre & Post & & \\
\hline Sodium, mmol/1 & $146.6 \pm 5.4$ & $145.2 \pm 3.8$ & $147.4 \pm 5.9$ & $142.8 \pm 5.0$ & $128-145$ & 0.221 \\
\hline Potassium, mmol/l & $4.8 \pm 0.4$ & $5.0 \pm 0.6$ & $4.7 \pm 0.4$ & $5.1 \pm 1.3$ & $3.6-5.1$ & 0.828 \\
\hline Chloride, $\mathrm{mmol} / \mathrm{l}$ & $108.4 \pm 3.4$ & $107.3 \pm 3.3$ & $107.6 \pm 4.4$ & $105.6 \pm 3.1$ & $98-108$ & 0.310 \\
\hline Calcium, mg/dl & $9.4 \pm 0.5$ & $9.5 \pm 0.4$ & $9.5 \pm 0.5$ & $9.7 \pm 1.3$ & $8-10$ & 0.683 \\
\hline Blood urea nitrogen ${ }^{\mathrm{b}}, \mathrm{mg} / \mathrm{dl}$ & $12.7 \pm 2.9$ & $12.2 \pm 2.5$ & $13.6 \pm 3.1$ & $13.0 \pm 3.1$ & $7-22$ & 0.428 \\
\hline Creatinine, mg/dl & $0.9 \pm 0.2$ & $0.9 \pm 0.1$ & $0.9 \pm 0.2$ & $0.9 \pm 0.3$ & $0.2-1.6$ & 0.794 \\
\hline Alkaline phosphatase ${ }^{\mathrm{b}}, \mathrm{U} / \mathrm{l}$ & $61.2 \pm 21.4$ & $60.2 \pm 12.9$ & $61.9 \pm 17.4$ & $65.4 \pm 25.4$ & $53-128$ & 0.328 \\
\hline Alanine transferase $\mathrm{e}^{\mathrm{b}}, \mathrm{U} / 1$ & $23.1 \pm 9.5$ & $22.4 \pm 4.4$ & $22.4 \pm 6.9$ & $26.5 \pm 14.1$ & $10-47$ & 0.439 \\
\hline Aspartate transferase ${ }^{\mathrm{b}}, \mathrm{U} / 1$ & $27.1 \pm 4.3$ & $26.2 \pm 2.2$ & $27.9 \pm 4.8$ & $29.9 \pm 7.3$ & $11-38$ & 0.176 \\
\hline Total bilirubin ${ }^{\mathrm{a}}, \mathrm{mg} / \mathrm{dl}$ & $0.6 \pm 0.1$ & $0.6 \pm 0.2$ & $0.6 \pm 0.1$ & $0.5 \pm 0.1$ & $0.2-1.6$ & 0.121 \\
\hline Albumin $^{\mathrm{a}}, \mathrm{g} / \mathrm{dl}$ & $3.9 \pm 0.3$ & $3.91 \pm 0.3$ & $4.0 \pm 0.3$ & $4.0 \pm 0.6$ & $3.3-5.5$ & 0.574 \\
\hline Total protein ${ }^{\mathrm{a}}, \mathrm{g} / \mathrm{dl}$ & $7.4 \pm 0.5$ & $7.4 \pm 0.4$ & $7.5 \pm 0.6$ & $7.8 \pm 1.4$ & $6.4-8.1$ & 0.395 \\
\hline $\mathrm{tCO}_{2}, \mathrm{mEq} / 1$ & $26.1 \pm 1.8$ & $26.2 \pm 1.9$ & $27.9 \pm 3.5$ & $26.2 \pm 3.5$ & $23-29$ & 0.823 \\
\hline
\end{tabular}

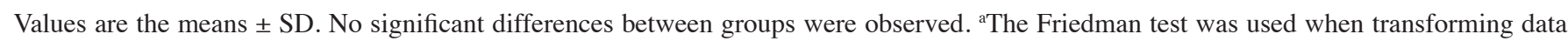
that did not achieve normality. ${ }^{\text {}}$ Transformed to achieve normality. TCJ, tart cherry juice.

weight was $88.77 \pm 12.62 \mathrm{~kg}(195.7 \pm 27.8$ pounds) and average BMI was $32.2 \pm 4.6 \mathrm{~kg} / \mathrm{m}^{2}$, indicating the group was overweight $\left(\mathrm{n}=5\right.$; BMI $\left.25.0-29.9 \mathrm{~kg} / \mathrm{m}^{2}\right)$ and obese $\left(\mathrm{n}=5 ; \geq 30.0 \mathrm{~kg} / \mathrm{m}^{2}\right)$ (Table II). There were 8 Caucasian females and 2 Caucasian males in the cohort.

Biomarkers of metabolic function. As part of the comprehensive metabolic panel, fasting glucose levels were measured at each laboratory visit. It was observed that 7 of the 10 participants exhibited fasting blood glucose levels $\geq 100 \mathrm{mg} / \mathrm{dl}$, which is suggestive of impaired fasting glucose and pre-diabetes (Table II). In total, 4 of the 5 overweight individuals and 3 of the 5 obese individuals displayed glucose levels $\geq 100 \mathrm{mg} / \mathrm{dl}$ with no clear association with BMI. There were no significant differences between pre- and post-consumption glucose concentrations within groups or between beverage groups, supporting no adverse effect of TCJ on glycemia.

In addition, no significant differences were noted between electrolyte levels when comparing pre- vs. post- treatment or between the juice and placebo groups. Plasma sodium, 
potassium, chloride and calcium levels were all within accepted, standardized reference ranges, indicating no perturbation in electrolyte balance (Table III). Following the consumption of TCJ for 4 weeks, the hepatic enzyme levels in plasma did not differ significantly between any of the groups. ALP, ALT and AST, hallmark indicators of liver health, were all within normal reference ranges, indicating no adverse effects, i.e., hepatotoxicity, of TCJ or the placebo beverage. Total bilirubin, albumin and total protein (albumin + globulins) levels were also within normal reference ranges, indicating normal liver function as well as renal function. Normal plasma BUN and creatinine concentrations confirmed the lack of adverse effects of TCJ consumption on renal function under the conditions of the present study.

\section{Discussion}

Few studies have evaluated the associations between the dietary intake of fruit juices, and intermediate biomarkers of cardiometabolic risk, particularly in the context of hepatic and renal function in individuals at-risk for or exhibiting metabolic syndrome $(11,28-30)$. SSBs are consumed globally and have been associated with adverse health outcomes, including weight gain, T2DM and CVD (31-34). Other studies have reported higher systolic blood pressure (hypertension) among those with higher SSB consumption, likely due to associated weight gain (35-37). A recent cohort study $(n=13,440$ adults $\geq 45$ years) indicated that each additional $355 \mathrm{ml}$ (12 oz) of SSB or fruit juice beverage consumed caused a significant 11 and $24 \%$ higher all-cause mortality risk, respectively (38). In the present 10 -week $2 \times 2$ crossover, randomized, placebo-controlled dietary intervention in overweight and obese participants (BMI $\geq 25.0 \mathrm{~kg} / \mathrm{m}^{2}$ ), no significant alterations were noted in hepatic or renal function from the start to the end of the study when comparing the TCJ to the placebo group. Dietary intake and physical activity levels were similar among all groups. In addition, no changes were noted in body composition (percentage body fat, lean body mass, etc.) or BMI after 4 weeks of beverage consumption. It was concluded that $100 \%$ TCJ does not exacerbate already existing risk factors, viz., elevated fasting blood glucose, in an at-risk (for chronic disease) population or affect adversely hepatic or renal function.

Replacing fruit juice with whole fruits is associated with a lower risk of developing chronic diseases, i.e., T2DM; thus, whole fruit is the preferred dietary means of nutrient consumption from fruits (39). However, there are positive studies supporting the benefits of fruit juice consumption. In children, $100 \%$ fruit juice was associated, in part, with reaching daily values of vitamin $\mathrm{C}$, folate and vitamin $\mathrm{K}$ intake (12). The consumption of deeply pigmented foods rich in polyphenolic anthocyanins (ACNs), with marked antioxidant and anti-inflammatory activity, has been shown to exert preventive effects against chronic diseases. In a placebo-controlled intervention ( $\mathrm{n}=57)$, ACN-rich juice consumption for 9 weeks caused DNA protective and antioxidant effects, which were also observed unexpectedly in the placebo group (15). The authors of that study proposed that vitamin $\mathrm{C}$ was responsible for the placebo effect. Conversely, the effect of ingestion of different white grape juices ( $7 \mu \mathrm{l} / \mathrm{g}$ body weight) on biochemical serum profiles and oxidative stress in the liver of adult Wistar rats did not alter biochemical parameters (40). The ingestion of both grape juices elevated glutathione and total antioxidant capacity, with no effects on glucose or uric acid although consumption of $480 \mathrm{ml}$ of antioxidant-rich Concord grape juice per day for 3 months increased insulin resistance and waist circumference in overweight individuals in a different clinical trial $(41,42)$. Indeed, the authors also previously demonstrated that ACN-rich TCJ did not adversely affect blood glucose, but that serum urate (uric acid) was significantly reduced in a population at risk for metabolic syndrome and potentially gouty arthritis $(43,44)$.

There has been increasing interest in $\mathrm{ACN}$-rich tart cherries and their juice due to cumulative myriad health benefits and their purported protection against the development and elaboration of chronic diseases, as reviewed by Kelley et al (45). For example, investigators have demonstrated in numerous studies that tart cherry and/or TCJ clearly reduces potentially damaging oxidative stress, an event thought to be involved in the etiology of several pathologies (46-49). Moreover, given that oxidative stress is closely linked to inflammation, it is not unexpected that TCJ has been shown to significantly reduce undesired inflammation in numerous studies $(45,47,50)$. There is also increasing information supporting an inhibitory role for TCJ in pro-inflammatory gouty arthritis and osteoarthritis, as well as the capacity to reduce exercise-induced pain, soreness and muscle damage often assumed, in large part, to be due to increased oxidative stress (47,51-53). Supportive evidence also suggests that tart cherries and TCJ can modulate risk factors for diabetes and CVD, which are also linked to oxidative stress (54-56). For example, TCJ reduces HbA1C levels, a marker of blood glucose control, in diabetic women with no changes in fasting glucose. Others have demonstrated reductions in both systolic and diastolic blood pressure presumably via, in part, the modulation of nitric oxide levels and vasorelaxation $(57,58)$. Collectively, there is considerable evidence demonstrating the health benefits from tart cherry and TCJ consumption.

There have been several reports that the dietary consumption of some fruit juices exerts adverse effects. For example, in female albino rats fed star fruit juice (dose range of $250-5,000 \mathrm{mg} / \mathrm{kg}$ ), acute studies suggested the juice was safe up to the highest level. However, after $48 \mathrm{~h}$, liver enzyme (AST, ALT and ALP), urea and creatinine levels were significantly higher in a dose-dependent manner compared to the control (19). Moreover, the authors of that study concluded that the juice of Averrhoa carambola was both nephrotoxic and hepatotoxic in rats after 28 days (4 weeks), a time interval used in the current study. In a different study, rats $(n=5)$ orally treated with juice for 14 days after initial storage of the juice for either 0 , 1 , or $3 \mathrm{~h}$, liver enzyme (ALT, ALP and AST), urea and serum creatinine levels were once again significantly elevated (19). Damage also occurred at the hepatocellular level with significantly increased serum ALT following the consumption of juice stored for $3 \mathrm{~h}$ (20). The ingestion of pomegranates has been associated with the deaths of young cattle without prior clinical signs, although marked weakness and discoloration of mucous membranes were noted in one animal. Gross pathological changes 
included widespread subcutaneous and serosal hemorrhages with acute periacinar to midzonal hepatocellular necrosis characteristic of toxicity (21). In a study on noni fruit (Morinda citrifolia), commonly used as a functional beverage with medicinal properties, mice were fed water extracts of fruit (two doses each). After 6 months, the study demonstrated that the fruit extract caused chronic toxicity at the highest dose $(2 \mathrm{mg} / \mathrm{ml}$ water $)$ with clear hepatocellular necrosis, reduced liver length, increased liver enzymes, i.e., AST and reduced albumin and ultimately $40 \%$ mortality within 3 months (22). In humans, 2 cases of hepatotoxicity following noni juice consumption were reported by Stadlbauer et al (23). A 29-year-old male with previous toxic hepatitis developed sub-acute hepatic failure (determined via transjugular or percutaneous liver biopsy) following the consumption of 1.51 noni juice over 3 weeks, mandating urgent liver transplantation. A 62-year-old woman without pre-existing liver disease or dysfunction, developed acute hepatitis following the consumption of 21 of noni juice over a period of 3 months (23). The bottle gourd (Lagenaria siceraria) also known as lauki, ghia or dudhi is prescribed as part of traditional medicine for T2DM, hypertension, liver diseases, weight loss and other associated problems. However, there have been reports of adverse effects after juice consumption with complaints of abdominal pain, diarrhea, and vomiting (with blood). Endoscopic results displayed profuse gastric bleeding with profound, frequent ulceration of the distal esophagus, stomach and duodenum. Liver enzymes levels were also elevated indicating hepatic toxicity (24). While there are a plethora of beneficial bioactive agents in fruits and consequently fruit juices, there may also be potentially deleterious molecules and/or precursors $(59,60)$. In rodent studies, the provision of juice obtained from Morinda citrifolia (noni) fruit caused significant hepatotoxicity, likely due to the anthraquinones in the seeds and skin, which exhibits quinone reductase inducer activity involved in detoxification of quinones. Studies report that anthraquinone activity is 40 -fold more effective than 1-sulforaphane, a bioactive organosulfur isothiocyanate in cruciferous vegetables $(22,23)$.

The fructose hypothesis alleges the fructose component common to all major caloric sweeteners and naturally occurring sweetened fruit juice plays a unique and causative role in the increasing rates of CVD, hypertension, T2DM, cancer and NAFLD. One report, however, concludes that fructose intake at normal population levels and patterns does not cause biochemical outcomes substantially different from other dietary sugars (61). Ounce for ounce, some $100 \%$ fruit juices may have more sugar than SSBs, but on average, most have a similar energy density and sugar content (62). For example, $250 \mathrm{ml}$ of apple juice typically contains $110 \mathrm{kcal}$ and $26 \mathrm{~g}$ of sugar; $250 \mathrm{ml}$ of cola typically contains $105 \mathrm{kcal}$ and 26.5 of sugar. TCJ $(240 \mathrm{ml})$ contains $159 \mathrm{kcal}$ and $33 \mathrm{~g}$ of sugar per cup ( $16-17 \mathrm{~g}$ fructose). An additional consideration is that $100 \%$ fruit juices, although nutrient-rich, contain little or no fiber which confers a higher glycemic index to juice.

The amounts of simple sugars and the relative ratios may also be a consideration. In a study comparing the fructose concentration of commonly consumed beverages, 15 beverages had a fructose-glucose ratio exceeding $55 \%$ with a mean fructose content of 59\% (63). In a study commissioned by the International Society of Beverage Technologists, 80 random beverages known to be sweetened with HFCS-55 were tested. The mean fructose content of these beverages was $55.6 \%$ (61). A number of beverages, however, have a fructose content $>55 \%$ and there may be significant biological differences in response to differing ratios, i.e., 50:50, 60:40, likely due to well-established differences between glucose and fructose metabolism $(62,64,65)$. In short, the excessive supply of fructose to the liver enhances hepatic de novo lipogenesis and increases lipid levels associated with hepatic insulin resistance. A 12 -week intervention where $13 \%$ of diet energy as fructose was served in the habitual diet of 71 men with abdominal obesity, an increased body weight, liver fat content (steatosis) and post-prandial TG levels were observed. Replacing energy requirement with $10 \%$ juice also significantly increased low density lipoprotein cholesterol (LDL-C), apolipoprotein B (apoB) and post-prandial TG levels compared to baseline levels (63). In a 6-month dietary intervention study, subjects consuming one liter of SSB/day exhibited increased TG, cholesterol and liver fat (60). In a previous study conducted in our laboratory, individuals consuming 8 ounces TCJ per day for 4 weeks exhibited a significant increase in erythrocyte sedimentation rate (ESR), an indicator of chronic inflammation, but not the TCJ suggesting the SSB was altering this biochemical parameter (43).

There are several limitations to the current study that may affect the interpretation of the results yet be relevant for the design of future studies. First, the present study was a small pilot study with 10 participants. As a result, the results may not be applicable to larger populations and may not be relevant all races, sexes and/or nationalities. Moreover, the small sample number, although generally considered acceptable for a pilot study, may have been limiting for elaborating potentially significant effects if present. Subsequent studies should aim for larger cohort sizes with more refined inclusion criteria as pilot studies reveal which are most likely amenable to intervention. Another consideration is the length of each arm and the washout period. Chronic consumption of TCJ beyond 4 weeks may lead to different results and although we noted no significant differences due to a carryover effect, e.g., 2-week washout period, this may be too short of an interval for other products. The experimental design, however, was based on other published designs. In the present study, a sweetened, artificially colored fruit punch was used, which arguably may not be as effective as desired for a placebo regarding optimal matching of astringency and the presence of sediment although the colors of the beverages were matched as closely as possible and the caloric and carbohydrate values were similar. Other studies have used fruit-flavored drink mixes, e.g., Kool-Aid, sports beverages, water, synthetic orange-flavored beverages, etc. supporting the placebo selection in the present study $(16,47,53)$. Furthermore, in a previous meta-analysis, Wang et al reported selections for placebo beverages in 12 studies, which included modified sports beverages, synthetic orange-flavored drinks, water, and a generic control drink matched for sugar composition (66). 
Important discrepancies between studies, such as the type of fruit juice, dose, duration, study design and measured outcomes contribute to inconsistencies in results between studies and complicates interpretation. As a result, it becomes difficult to provide evidence-based public recommendations regarding the consumption of fruit juices and potential effects on metabolic parameters (63). Given that no association purportedly exists between $100 \%$ fruit juice and most risk factors for CVD, including changes in glucose homeostasis, lipid concentrations and blood pressure, the current evidence does not suggest that $100 \%$ fruit juice consumption markedly affects the risk of CVD $(34,59,67)$. Evidence exists that $100 \%$ fruit juice is associated with major chronic diseases, but the existing body of evidence is too limited to robustly support any expert opinion recommending changing the current guidelines on $100 \%$ fruit juice consumption (8). Presently, the World Health Organization (WHO) recommends reducing the intake of free sugars to $<10 \%$ and ideally $<5 \%$ of the total daily energy intake (63). More randomized, placebo-controlled clinical trials are required to confirm the health effects of consuming $100 \%$ fruit juice and cohort analyses should report both energy-adjusted and energy-unadjusted associations $(8,68)$.

\section{Acknowledgements}

The authors wish to thank Mr. Michael Stroup (Research Technician, Arizona State University) for providing assistance with the phlebotomy.

\section{Funding}

The present study was supported by a grant (no. NCT03638362) from the Cherry Marketing Institute, (Dewitt, MI, USA). The funding source had no role in any aspect of the study design, data collection or analysis, writing of the manuscript or decision to publish.

\section{Availability of data and materials}

All data generated or analyzed during this study are included in this published article or are available from the corresponding author on reasonable request.

\section{Authors' contributions}

KRM initiated and designed the study and secured the funding from the Cherry Marketing Institute. KRM interpreted the data and prepared the manuscript. JB and LB recruited, screened and provided informed consent to respondents under the supervision of KRM, as well as collected, processed and analyzed, in part, data, samples and questionnaires. All authors critically reviewed the manuscript and all authors read and approved the final manuscript.

\section{Ethics approval and consent to participate}

The present study was approved by the Arizona State University Institutional Review Board. Prior to entering the study, all respondents and participants were provided written informed consent.

\section{Patient consent for publication}

Not applicable.

\section{Competing interests}

The authors declare no competing financial and/or personal interests.

\section{References}

1. Bo S, Fadda M, Fedele D, Pellegrini M, Ghigo E and Pellegrini N: A critical review on the role of food and nutrition in the energy balance. Nutrients 12: 1161, 2020.

2. Seferidi P, Millett C and Laverty AA: Sweetened beverage intake in association to energy and sugar consumption and cardiometabolic markers in children. Pediatr Obes 13: 195-203, 2018.

3. Malik VS and Hu FB: Sugar-sweetened beverages and cardiometabolic health: An update of the evidence. Nutrients 11: 1840, 2019.

4. Gill J and Sattar N: Fruit juice: Just another sugary drink? Lancet Diabetes Endocrinol 2: 444-446, 2014.

5. Ruanpeng D, Thongprayoon C, Cheungpasitporn W and Harindhanavudhi T: Sugar and artificially sweetened beverages linked to obesity: A systematic review and meta-analysis. QJM 110: 513-520, 2017.

6. Odegaard AO, Koh WP, Arakawa K, Yu MC and Pereira M: Soft drink and juice consumption and risk of physician-diagnosed incident type 2 diabetes: The Singapore Chinese health study. Am J Epidemiol 171: 701-708, 2010.

7. Ng SW, Slining MM and Popkin BM: Use of caloric and noncaloric sweeteners in US consumer packaged foods, 2005-2009. J Acad Nutr Diet 112: 1828,1834.e1-e6, 2012.

8. Auerbach BJ, Dibey S, Vallila-Buchman P, Kratz M and Krieger J: Review of $100 \%$ fruit juice and chronic health conditions: Implications for sugar-sweetened beverage policy. Adv Nutr 9: 78-85, 2018.

9. Chanchlani N and Russell E: Fruit consumption and risk of type 2 diabetes: Results from three prospective longitudinal cohort studies. Student BMJ 21, 2013.

10. Hirahatake KM, Jacobs DR, Shikany JM, Jiang L, Wong ND, Steffen LM and Odegaard AO: Cumulative intake of artificially sweetened and sugar-sweetened beverages and risk of incident type 2 diabetes in young adults: The coronary artery risk development in young adults (CARDIA) study. Am J Clin Nutr 110: 733-741, 2019.

11. Lorenzoni G, Minto C, Vecchio MG, Zec S, Paolin I, Lamprecht M, Mestroni L and Gregori D: Fruit and vegetable concentrate supplementation and cardiovascular health: A systematic review from a public health perspective. J Clin Med 8: 1914, 2019.

12. Byrd-Bredbenner C, Ferruzzi MG, Fulgoni VL III, Murray R, Pivonka E and Wallace TC: Satisfying America's fruit gap: Summary of an expert roundtable on the role of $100 \%$ fruit juice. J Food Sci 82: 1523-1534, 2017.

13. Vartanian LR, Schwartz MB and Brownell KD: Effects of soft drink consumption on nutrition and health: A systematic review and meta-analysis. Am J Public Health 97: 667-675, 2007.

14. Chang SK, AlasalvarC and Shahidi F: Superfruits: Phytochemicals, antioxidant efficacies, and health effects-a comprehensive review. Crit Rev Food Sci Nutr 59: 1580-1604, 2019.

15. Bakuradze T, Tausend A, Galan J, Groh IAM, Berry D, Tur JA, Marko D and Richling E: Antioxidative activity and health benefits of anthocyanin-rich fruit juice in healthy volunteers. Free Radic Res 53: 1045-1055, 2019.

16. Wijarnpreecha $\mathrm{K}$, Thongprayoon $\mathrm{C}$, Edmonds PJ and Cheungpasitporn W: Associations of sugar- and artificially sweetened soda with nonalcoholic fatty liver disease: A systematic review and meta-analysis. QJM 109: 461-466, 2016.

17. Bomback AS, Katz R, He K, Shoham DA, Burke GL and Klemmer PJ: Sugar-sweetened beverage consumption and the progression of chronic kidney disease in the multi-ethnic study of atherosclerosis (MESA). Am J Clin Nutr 90: 1172-1178, 2009. 
18. Cheungpasitporn W, Thongprayoon $\mathrm{C}$, O'Corragain OA Edmonds PJ, Kittanamongkolchai $\mathrm{W}$ and Erickson SB: Associations of sugar-sweetened and artificially sweetened soda with chronic kidney disease: A systematic review and meta-analysis. Nephrology (Carlton) 19: 791-797, 2014.

19. Aba PE and Amadi AU: Evaluation of the possible hepatotoxic and nephrotoxic potentials of the Averrhoa carambola juice extract in female albino rats. J Basic Clin Physiol Pharmacol 31, 2019

20. Khoo ZY, Teh CC, Rao NK and Chin JH: Evaluation of the toxic effect of star fruit on serum biochemical parameters in rats. Pharmacogn Mag 6: 120-124, 2010.

21. Hawes MH and Gill IJ: Hepatotoxicosis in cattle associated with consumption of Punica granatum (pomegranate). Aust Vet J 96: 408-410, 2018.

22. Mohamad-Shalan NAA, Mustapha NM and Mohamed S: Chronic toxicity evaluation of Morinda citrifolia fruit and leaf in mice. Regul Toxicol Pharmacol 83: 46-53, 2017.

23. Stadlbauer V, Fickert P, Lackner C, Schmerlaib J, Krisper P, Trauner M and Stauber RE: Hepatotoxicity of NONI juice: Report of two cases. World J Gastroenterol 11: 4758-4760, 2005.

24. Indian Council of Medical Research Task Force: Assessment of effects on health due to consumption of bitter bottle gourd (Lagenaria siceraria) juice. Indian J Med Res 135: 49-55, 2012.

25. Rebholz CM, Young BA, Katz R, Tucker KL, Carithers TC, Norwood AF and Correa A: Patterns of beverages consumed and risk of incident kidney disease. Clin J Am Soc Nephrol 14: 49-56, 2019.

26. Yuzbashian E, Asghari G, Mirmiran P, Zadeh-Vakili A and Azizi F: Sugar-sweetened beverage consumption and risk of incident chronic kidney disease: Tehran lipid and glucose study. Nephrology (Carlton) 21: 608-616, 2016.

27. Stumpf MAM, Schuinski AFM, Baroni G and Ramthun M: Acute kidney injury with neurological features: Beware of the star fruit and its caramboxin. Indian J Nephrol 30: 42-46, 2020.

28. Ferreira-Pêgo C, Babio N, Bes-Rastrollo M, Corella D, Estruch R, Ros E, Fitó M, Serra-Majem L, Arós F, Fiol M, et al: Frequent consumption of sugar- and artificially sweetened beverages and natural and bottled fruit juices is associated with an increased risk of metabolic syndrome in a mediterranean population at high cardiovascular disease risk. J Nutr 146: 1528-1536, 2016.

29. Yu Z, Ley SH, Sun Q, Hu FB and Malik VS: Cross-sectional association between sugar-sweetened beverage intake and cardiometabolic biomarkers in US women. Br J Nutr 119 : $570-580,2018$

30. Kosova EC, Auinger P and Bremer AA: The relationships between sugar-sweetened beverage intake and cardiometabolic markers in young children. J Acad Nutr Diet 113: 219-227, 2013.

31. Imamura F, O'Connor L, Ye Z, Mursu J, Hayashino Y, Bhupathiraju SN and Forouhi NG: Consumption of sugar sweetened beverages, artificially sweetened beverages, and fruit juice and incidence of type 2 diabetes: Systematic review, meta-analysis, and estimation of population attributable fraction. BMJ 351: h3576, 2015.

32. Jayalath V, de Souza RJ, Ha V, Mirrahimi A, Blanco-Mejia S, Di Buono M, Jenkins AL, Leiter LA, Wolever TM, Beyene J, et al: Sugar-sweetened beverage consumption and incident hypertension: A systematic review and meta-analysis of prospective cohorts. Am J Clin Nutr 102: 914-921, 2015.

33. Kim Y and Je Y: Prospective association of sugar-sweetened and artificially sweetened beverage intake with risk of hypertension. Arch Cardiovasc Dis 109: 242-253, 2015.

34. Malik VS, Popkin BM, Bray GA, Després JP and Hu FB: Sugar-sweetened beverages, obesity, type 2 diabetes mellitus, and cardiovascular disease risk. Circulation 121: 1356-1364, 2010.

35. Ambrosini GL, Oddy WH, Huang RC, Mori TA, Beilin LJ and Jebb SA: Prospective associations between sugar-sweetened beverage intakes and cardiometabolic risk factors in adolescents. Am J Clin Nutr 98: 327-334, 2013.

36. Hoare E, Varsamis P, Owen N, Dunstan DW, Jennings GL and Kingwell BA: Sugar- and intense-sweetened drinks in Australia: A systematic review on cardiometabolic risk. Nutrients 9: 1075, 2017.

37. Malik VS, Pan A, Willett WC and Hu FB: Sugar-sweetened beverages and weight gain in children and adults: A systematic review and meta-analysis. Am J Clin Nutr 98: 1084-1102, 2013.

38. Collin LJ, Judd S, Safford M, Vaccarino V and Welsh JA: Association of sugary beverage consumption with mortality risk in US adults: A secondary analysis of data from the REGARDS study. JAMA Netw Open 2: e193121, 2019.
39. Ravn-Haren G, Dragsted LO, Buch-Andersen T, Jensen EN, Jensen RI, Németh-Balogh M, Paulovicsová B, Bergström A, Wilcks A, Licht TR, et al: Intake of whole apples or clear apple juice has contrasting effects on plasma lipids in healthy volunteers. Eur J Nutr 52: 1875-1889, 2013.

40. Kovaleski ES, Gonçalves LK, Bortolato G, Marinho JP, Silva LFL, Russo M, Agostini F, Funchal C and Dani C: Effects of the ingestion of different kinds of white grape juice (Vitis labrusca) during adolescence on body weight, biochemical parameters and oxidative stress in liver of adult Wistar rats. Food Chem 291: 110-116, 2019.

41. Hollis JH, Houchins JA, Blumberg JB and Mattes RD: Effects of concord grape juice on appetite, diet, body weight, lipid profile, and antioxidant status of adults. J Am Coll Nutr 28: 574-582, 2009.

42. Toaldo IM, Cruz FA, da Silva EL and Bordignon-Luiz MT: Acute consumption of organic and conventional tropical grape juices (Vitis labrusca L.) increases antioxidants in plasma and erythrocytes, but not glucose and uric acid levels in healthy individuals. Nutr Res 36: 808-817, 2016.

43. Martin KR, Burrell L and Bopp J: Authentic tart cherry juice reduces markers of inflammation in overweight and obese subjects: A randomized, crossover pilot study. Food Funct 9: 5290-5300, 2018

44. Martin KR and Coles KM: Consumption of $100 \%$ tart cherry juice reduces serum urate in overweight and obese adults. Curr Dev Nutr 3: nzz011, 2019.

45. Kelley DS, Adkins Y and Laugero KD: A Review of the health benefits of cherries. Nutrients 10: 368, 2018.

46. Traustadóttir T, Davies SS, Stock AA, Su Y, Heward CB, Roberts LJ II and Harman SM: Tart cherry juice decreases oxidative stress in healthy older men and women. J Nutr 139: 1896-1900, 2009.

47. Bell PG, Walshe IH, Davison GW, Stevenson E and Howatson G: Montmorency cherries reduce the oxidative stress and inflammatory responses to repeated days high-intensity stochastic cycling. Nutrients 6: 829-843, 2014.

48. Garrido M, Espino J, González-Gómez D, Lozano M, Cubero J, Toribio-Delgado AF, Maynar-Mariño JI, Terrón MP, Muñoz JL, Pariente JA, et al: A nutraceutical product based on Jerte Valley cherries improves sleep and augments the antioxidant status in humans. E-SPEN J 4: e321-e323, 2009.

49. Garrido M, Gonzalez-Gomez D, Lozano M, Barriga C, Paredes SD and Rodriguez AB: Characterization and trials of a Jerte Valley cherry product as a natural antioxidant-enriched supplement. Ital J Food Sci 25: 90-97, 2013

50. Lynn A, Mathew S, Moore C, Russell J, Robinson E, Soumpasi V and Barker M: Effect of a tart cherry juice supplement on arterial stiffness and inflammation in healthy adults: A randomised controlled trial. Plant Foods Hum Nutr 69: 122-127, 2014

51. Bowtell JL, Sumners DP, Dyer A, Fox P and Mileva KN: Montmorency cherry juice reduces muscle damage caused by intensive strength exercise. Med Sci Sports Exerc 43: 1544-1551, 2011.

52. Zhang Y, Neogi T, Chen C, Chaisson C, Hunter DJ and Choi HK: Cherry consumption and decreased risk of recurrent gout attacks. Arthritis Rheum 64: 4004-4011, 2012

53. Howatson G, McHugh MP, Hill JA, Brouner J, Jewell AP, Van Someren KA, Shave RE and Howatson SA: Influence of tart cherry juice on indices of recovery following marathon running. Scand J Med Sci Sports 20: 843-852, 2010.

54. Saleh FA, El-Darra N and Raafat K: Hypoglycemic effects of Prunus cerasus L. pulp and seed extracts on Alloxan-induced diabetic mice with histopathological evaluation. Biomed Pharmacother 88: 870-877, 2017.

55. Snyder SM, Zhao B, Luo T, Kaiser C, Cavender G, Hamilton-Reeves J, Sullivan DK and Shay NF: Consumption of quercetin and quercetin-containing apple and cherry extracts affects blood glucose concentration, hepatic metabolism, and gene expression patterns in obese C57BL/6J high fat-fed mice. J Nutr 146: 1001-1007, 2016.

56. Lachin T: Effect of antioxidant extract from cherries on diabetes. Recent Pat Endocr Metab Immune Drug Discov 8: 67-74, 2014.

57. Medina-Remón A, Tresserra-Rimbau A, Pons A, Tur JA, Martorell M, Ros E, Buil-Cosiales P, Sacanella E, Covas MI, Corella D, et al: Effects of total dietary polyphenols on plasma nitric oxide and blood pressure in a high cardiovascular risk cohort. The PREDIMED randomized trial. Nutr Metab Cardiovasc Dis 25: 60-67, 2015. 
58. Miranda AM, Steluti J, Fisberg RM and Marchioni DM: Association between polyphenol intake and hypertension in adults and older adults: A population-based study in Brazil. PLoS One 11: e0165791, 2016.

59. Narain A, Kwok CS and Mamas MA: Soft drink intake and the risk of metabolic syndrome: A systematic review and meta-analysis. Int J Clin Pract 71, 2017.

60. Maersk M, Belza A, Stødkilde-Jørgensen H, Ringgaard S Chabanova E, Thomsen H, Pedersen SB, Astrup A and Richelsen B: Sucrose-sweetened beverages increase fat storage in the liver, muscle, and visceral fat depot: A 6-mo randomized intervention study. Am J Clin Nutr 95: 283-289, 2012.

61. White JS: Challenging the fructose hypothesis: New perspectives on fructose consumption and metabolism. Adv Nutr 4: 246-256, 2013.

62. White JS, Hobbs LJ and Fernandez S: Re. 'Fructose content in popular beverages made with and without high fructose corn syrup'. Nutrition 31: 417-418, 2015.

63. Pepin A, Stanhope KL and Imbeault P: Are fruit juices healthier than sugar-sweetened beverages? A review. Nutrients 11: 1006, 2019.

64. White JS, Hobbs LJ and Fernandez S: Fructose content and composition of commercial HFCS-sweetened carbonated beverages. Int J Obes (Lond) 39: 176-182, 2015.
65. Walker RW, Dumke KA and Goran MI: Fructose content in popular beverages made with and without high-fructose corn syrup. Nutrition 30: 928-395, 2014.

66. Wang B, Liu K, Mi M and Wang J: Effect of fruit juice on glucose control and insulin sensitivity in adults: A meta-analysis of 12 randomized controlled trials. PLoS One 9: e95323, 2014.

67. Marriott BP, Olsho L, Hadden L and Connor P: Intake of added sugars and selected nutrients in the United States, national health and nutrition examination survey (NHANES) 2003-2006 Crit Rev Food Sci Nutr 50: 228-258, 2010.

68. Popkin BM, Armstrong LE, Bray GM, Caballero B, Frei B and Willett WC: A new proposed guidance system for beverage consumption in the United States. Am J Clin Nutr 83: 529-542, 2006.

This work is licensed under a Creative Commons Attribution-NonCommercial-NoDerivatives 4.0 International (CC BY-NC-ND 4.0) License. 